\title{
This might be the PLACE. Spelling out a covert D in Fodom spatial PPs
}

\author{
Tommaso Mattiuzzi \\ University of Frankfurt \\ mattiuzzi@em.uni-frankfurt.de
}

Received: 15-03-21

Accepted: 30-9-21

Published: 22-02-22

How to cite: Tommaso Mattiuzzi. 2022. This might be the PLACE. Spelling out a covert D in Fodom spatial PPs. RLLT17, eds. Ora Matushansky, Laurent Roussarie, Michela Russo, Elena Soare \& Sophie Wauquier. Special issue of Isogloss Open Journal of Romance Linguistics 8(2)/21, 1-20.

DOI: https://doi.org/10.5565/rev/isogloss.125

\begin{abstract}
This article presents novel data on the yet unnoticed phenomenon of article-drop in the variety of Livinallongo/Fodom (Ladin). The fundamental aim is to provide a morphosyntactic analysis capturing the following: a) omission of the definite article is only possible in (spatial) PPs and with a specific set of data; b) the noun can be interpreted as a specific definite as well as a weak definite; c) omission interacts with structural properties of the nominal complement like Number features and the structural type of nominal modifiers. The account developed here builds on the hypothesis that despite appearances article-drop contexts in Fodom feature an active D category in their structure, which is licensed by the head noun via phrasal Spell Out (cf. Starke 2009; 2011; Baunaz and Lander 2018b; Caha 2009; 2018; Pantcheva 2011, a.o.) and is argued to be superior to alternative accounts in terms of selection of a null $\mathrm{D}$ by the $\mathrm{P}^{0}$ head or movement of the noun.
\end{abstract}

Keywords: article-drop, D, PPs, location, PLACE 


\section{Introduction}

This article deals with article-drop in the variety of Livinallongo/Fodom, which is part of the Ladin area ${ }^{1}$. The fundamental aim is to describe and develop a morphosyntactic analysis of the phenomenon, which, to my knowledge, is still unnoticed in the literature $^{2}$. The account developed here builds on the hypothesis that - despite appearances - article-drop contexts in Fodom feature an active D category in their structure, which is licensed by the head noun via phrasal Spell Out (cf. Starke 2009 and ff., Caha 2009, 2018, Pantcheva 2011, Baunaz and Lander 2018a a.o.). Building on widespread assumptions on the general structural make-up of DPs (cf. e.g. Guglielmo Cinque 2005; 2010b; Alexiadou, Haegeman, and Stavrou 2008), this is shown to happen only in a specific configuration, in which the DP is only specified for default values (here dubbed 'slim' DP). This proposal thus provides a non-stipulative way to capture the correlation between internal properties of the DP, structural interactions involving the D-layer, and their interpretive reflexes.

Fodom article-drop is restricted to PPs (1a), where a specific set of singular count nouns can exceptionally occur articleless ${ }^{3}$, despite requiring the article in other structural environments (1b), as is generally the case in Romance:
a. 1 rucsòch 1 é davò porta (de mia ciauna)
the backpack $=$ SUBJ.3SG be.3SG behind door (of my room)
'The backpack is behind the door (of my bedroom)'
b. no ciafiéie a tré nca *(1) let
no be.able.1SG to drag.INF to.here *(the) bed
'I can't drag here the bed'

The article focusses on spatial $\mathrm{PPs}^{4}$. Interestingly, bare nouns in cases like (1) can get a definite reading and allow pronominal resumption. In light of well-established generalizations on D in Romance (cf. e.g. Longobardi 1994 and ff.), this is taken to point to the conclusion that article-drop contexts feature DP complements, and not simple NPs. Moreover, article-drop is structurally restricted. Omission of the article is thus only possible with singular nouns, either non modified, or combined with an argumental $\mathrm{PP}^{5}$ (as shown in 1a). Instead, a blocking effect is observed with plural

$1 \quad$ Cf. Casalicchio (2020a; 2020b)

2 This is not to say that it is unparalleled: so-called 'bare PPs' are attested in several languages (De Swart 2015). The closest parallel is with locative PPs without an article in Italian, for which Franco and Lorusso (2019) propose that the two relevant Ps, in "in" and $a$ "at/to", select bare NP and DPs with N-to-D movement of proper names à la Longobardi (1994), respectively. A full discussion of this approach and its potential extension to Fodom is not possible here, but cf. section 4 for the differences between article-drop in Fodom and bare PPs in general.

3 For convenience, in what follows 'bare nouns' will be used to refer to instances of singular count nouns exceptionally lacking an introducing determiner, abstracting away from other cases of articleless nouns like bare mass and bare plurals.

4 Interestingly, preliminary evidence suggests that temporal PPs exhibit parallel behavior, cf. 3.1 below.

$5 \quad$ On the relevant distinction and the status of argumental PPs, cf. 3.3 below. 
marking on the noun and almost all kinds of nominal modifiers. The analysis builds on the intuition that nominal structure can be more or less complex depending on which features and DP-internal elements are present. Thus, article-drop only occurs in the simplest configuration (dubbed 'slim DP'), and article-drop is blocked due to structural complexity (cf. 3.3). It will be argued that all of the above properties (and the lexical restrictions of what nouns head the relevant bare complements) can be straightforwardly accounted for by taking nouns allowing article-drop to be able to Spell Out a D level.

Unless otherwise noted, all examples discussed in the paper are original data, and have been collected through a total of three questionnaires. The first was completed by informants during live interviews and included a total of 192 items, while the latter had to be realized in a written form, and consisted of 36 and 37 items, respectively. Two informants participated to all questionnaires, and two more only completed the third one. Three of the four informants resided in Pieve di Livinallongo/Fodom, and the fourth one in Salesei di Sotto, a different village in the same municipality. Items required translations of sentences from Standard Italian into Fodom and vice versa, or acceptability judgements on pre-given translations. The latter were asked in the form of multiple-choice items, whereby the informants chose one of two alternative translations of a given sentence, both or neither.

The article is organized as follows. The main features of Fodom article drop are systematically examined in section 2 . The analysis is developed in section 3 , where it is also argued to be superior to two potential alternative approaches. Section 4 concludes and discusses some open questions.

\section{Introducing Fodom article-drop}

\subsection{Productivity of article-drop}

In order to treat examples like (1) above as cases of article-drop, it has to be shown that a grammatical regularity is indeed at play. Alternatively, one could take such cases as idiomatized combinations of specific preposition-noun pairings that have been fixed in the Fodom lexicon.

This section will show that Fodom has productive article-drop in spatial PPs, with the qualification that this can occur only with specific nouns. Three arguments support this claim. Starting from the first argument, article-drop is attested with all kinds of PP constructions. (1a) above and (2) show cases involving simple prepositional PPs:

$$
\begin{aligned}
& \text { nos son bele chilò nte boteiga } \\
& \text { we be.1PL already here in shop } \\
& \text { 'We're already here in/at the shop' }
\end{aligned}
$$

However, Fodom also has Circumpositional PPs featuring 'particle-like' elements as the postnominal element (3a). As a third kind of PP-construction, Fodom also has complex prepositions made up by combining a particle-like element (e.g. su "on") with the generic locative preposition $n$ "in"(3b). As anticipated, article-drop is observed in these two cases as well:

$$
\begin{aligned}
& \text { a. } 1 \text { cián } 1 \text { dormiva sot taula ite } \\
& \text { the dog =3SG sleep.IPFV. } 3 \text { under table inside } \\
& \text { 'The dog was sleeping under the table' }
\end{aligned}
$$


b. son jus sun tët per vedei le stele

be.1PL gone on.in roof for watch.INF the star.PL

'We went on the roof to watch the stars'

Thus, no restrictions are observed on the structural kind of constructions that article drop is compatible with.

As a second argument supporting the productive status of article-drop in Fodom, multiple P-N combinations are possible in omission contexts. Thus, the same noun can occur in articleless PPs headed by different prepositions. This is exemplified in (4) below for two representative nouns, namely pòrta "door"6.

(4) a. davò pòrta "behind the door", prò pòrta "near/at the door", davánt pòrta "in front of the door", sun pòrta de stala "on the door of the stable", etc.

b. sun taula "on the table", (di)ntourn taula "around the table", soura taula "over the table", davò taula ite "behind/at the table", etc.

Moreover, the data also support the specular observation, namely one and the same preposition/P item can be combined with many different bare complements. This is shown in (5) below for davò "behind", davánt "in front of":

a. davò pòrta "behind the door", davò usc "behind the door", davò ciampanil "behind the bell tower", davò taula ite "behind/at the table", etc.

b. davánt pòrta "in front of the door", davánt viere de ciesadafuoch "in front of the kitchen window", davánt gliejia "in front of the church", etc.

These examples strongly argue that we are not dealing with just a handful of fixed expressions. As a sidenote, apart from the sheer number of possible combinations, the conclusion is strengthened by the observation that the meaning of the expressions exemplified above looks straightforwardly compositional.

As anticipated, the claim that article-drop in Fodom PPs is productive needs elaboration. Given in (6) below is a list of Fodom prepositions and circumpositions, which is meant to further exemplify the variety of items allowing article-drop. An interesting feature of the phenomenon is that the "functional' ( $n$ "in", nte "in") vs. 'lexical' (davánt "before/in front of", (di)ntourn "around", etc.) status of the preposition (cf. e.g. Cinque 2010a) turns out to be irrelevant with respect to the availability of article-drop:

$$
\begin{aligned}
& n \text { "in", nte "in", davánt "before/in front of", davò/davò. . . ite "behind", } \\
& \text { (di)ntourn "around", prò "close to", dilongia "in front of", sot "under", soura } \\
& \text { "over", sot...ite "under", soura...via "over/across", sun "on", etc. }
\end{aligned}
$$

On the other hand, however, only a specific set of nouns allow article drop. Namely, their referent is always either an element which is prototypically a part of a conventional space in the household (7a), like the table and the stove in a kitchen, the bed and the wardrobe in a bedroom, etc., or of the outdoor space (7b) (at least in the Fodom valley), like a salient part of a village (e.g. the main square, the church, etc.), or a landmark (e.g. the wood, the road, the bridge, etc.):

6 The list in (4) is partially integrated with examples drawn from the "TALL Corpuslad" (Tratament Automatich dl Lingaz Ladin). 
(7) a. Domestic space: pòrta/usc "door", tët "roof", let "bed", almièrch "wardrobe", taula "table", fuoch/fornèl "stove", vière "window", cujina "kitchen", majon "shed", stala "stable", etc.

b. Outdoor space: plaza "square", cèsa "house", gliejia "church", scòla "school", boteiga "shop", strada "road", bòsch "wood", etc.

Thus, article-drop occurs with nouns that form a coherent set as regards the pragmatic salience of their referents. That is, the objects identified by these nouns are easily construed as points of spatial reference. Now, stemming from Talmy (1975), much literature on locative PPs (cf. Asbury et al. 2008) identifies different elements in the cognitive and semantic structure underlying spatial relations. Specifically, an object that is located or moving with respect to another object is dubbed 'Figure', while the object serving as the reference point for the location or motion of the Figure is called 'Ground'. To rephrase the present generalization in these terms, then, this set of nouns in Fodom could be described as denoting 'prototypical Grounds'. As such, this subregularity further argues against taking these constructions to be fully idiomatized.

At the same time, this pragmatic property is insufficient as an explanation, as it turns out. The data indicate that not all nouns fitting this description are compatible with article-drop. For instance, this is the case for altalena "swing" and bar "bar"7. Therefore, these contrasts must have a deeper source. In section 3, this state of affairs will be argued to result from the interaction of two basic ingredients: the regular derivation of a P+DP structure, and the peculiar way this specific set of nouns realizes the DP-portion of such structure, yielding article-drop. Following standard nanosyntactic assumptions (cf. Starke 2009 and ff.), the latter will be couched in terms of Spell Out properties of these nouns which are directly encoded in their lexical entry. An implication relation emerges, namely all nouns endowed with the relevant Spell Out properties also share the pragmatic property described above. Instead, the reverse does not hold, accounting for the impossibility of article-drop with nouns like altalena and bar.

To sum up, then, article-drop turns out to be a productive phenomenon in Fodom, attested in all kinds of PP structures and with all prepositions, and to be sensitive to properties of the noun heading the nominal complement.

\subsection{Interpretation of the noun in article-drop contexts}

Crucial information on the structure of article-drop constructions in Fodom can be gathered by examining the interpretive properties of the noun in omission context. The main conclusion of this section is that the nominal complement is ambiguous between a 'regular' definite and a weak definite ${ }^{8}$ (Carlson and Sussman 2005) reading in articleless PPs. Both of them point to the presence of covert functional layers in the structure of the nominal phrase, which thus turns out to be richer that what might be expected judging from their superficial 'bareness'.

$7 \quad$ Arguably, a swing may well be construed as a typical part of a location like a playground or a private garden, and a bar is a typical meeting point even in a small village. Still, altalena and bar resist article-drop. Now, this might be connected to the fact that they are both loans from Standard Italian. Still, this fits well within the general conclusion argued for in the text, namely that article-drop in Fodom is tied to lexical properties of the nouns.

$8 \quad$ Here 'weak definites' refers to definite phrases exhibiting typical properties of weakly referential nominals, e.g. discourse opacity and number neutrality (Aguilar-Guevara, Le Bruyn, and Zwarts 2014). Cf. section 3.2. for details. 
Descriptively, there is evidence that the noun can get a definite and specific reading in article drop contexts. Minimally, it must be assumed to have strong reference, in that pronominal resumption of its referent is possible:

$$
\begin{aligned}
& \text { chi é =lo che } 1 \text { a metù i ciauzèi sun let? } \\
& \text { who be. } 3=3 \mathrm{SG} \text { that }=3 \mathrm{SG} \text { have. } 3 \text { put.PTCP the shoes on.in bed } \\
& \mathrm{L} \text { é dut paz! } \\
& =3 \mathrm{SG} \text { be. } 3 \text { all dirty } \\
& \text { 'Who put the shoes on the bed? It's all dirty!' }
\end{aligned}
$$

On top of that, it should be added that PPs with article-drop are both accepted and produced by informants as translations of Italian expressions that are only felicitous under a definite reading. That is, in cases like in (9a) there is an active presupposition that there be a unique window in the relevant context, and the same goes for examples like (9b), where it is even more evident that the bare noun has a specific and unique referent (here, the only closet in the bedroom of the speaker):
a. 1 é senté davánt viere de cesadafuoch $=3 \mathrm{SG}$ be .3 sit.PTCP before window of kitchen
'He's sitting in front of the kitchen window'
b. nte almièrch de mia ciauna è bele cialé

in wardrobe of my room have.1SG already watch.PTCP

'I've already checked in my bedroom closet'

However, at least sometimes a generic/weak definite reading is possible as well. Indications to this conclusion come from two main diagnostics. One is the fact that sloppy identification of the referent is possible under ellipsis (cf. e.g. Aguilar-Guevara and Zwarts 2011; Carlson and Sussman 2005). For instance, it is possible to understand (10) as involving two different doors:

(10) 1 Carlo 1 a desmentié 1 rucsòch davò porta de ciauna, the Carlo $=3 \mathrm{SG}$ have .3 forgotten the backpack behind door of room e la Martina ence and the Martina too 'Carlo forgot his backpack behind the bedroom door, and Martina did too'

The second piece of evidence is that a number neutral interpretation appears to be available in cases like (11), where the most salient reading is a distributive one, where each of the people in the set picked up by the quantifier is in their respective bed:

$$
\begin{aligned}
& \text { co } 1 \text { a scomencé } 1 \text { temporal sonva duc nte let } \\
& \text { when =3SG have. } 3 \text { begun the storm be.IPFV.1PL all.PL in bed } \\
& \text { 'When the storm began, we were all in bed' }
\end{aligned}
$$

Thus, nouns in article-drop contexts can essentially receive the same readings as if they were regular definites ${ }^{9}$. As mentioned, this argues in favor of an active D-layer in their structures.

\footnotetext{
$9 \quad$ I thank one of the reviewers for highlighting this point.
} 


\subsection{Article-drop is structurally restricted}

Finally, a crucial observation is that the distribution of article-drop in Fodom PPs is subject to systematic structural restrictions. These are tied to internal structural properties of the nominal complement, namely the value specified for Number features and the presence and the kind of nominal modifiers. Thus, article-drop is only possible with singular nouns, either non-modified or modified by an argumental PP. An example for each case is given below in (12a) and (12b), respectively:

$$
\begin{aligned}
& \text { a. } 1 \text { é na sié ntourn cèsa } \\
& \text { =3SG be. } 3 \text { a hedge around home }
\end{aligned}
$$

'There's a hedge around (our/the) house'

b. son jus a mëssa nte gliejia d'Andrác be.1PL gone to mass in church of Andrác

'We went to Mass in the church of Andrác'

In all other cases article-drop is impossible. This includes non-modified plural nouns (13a) and any noun modified by a numeral (13b), a prenominal (13c) or postnominal (13d) adjective, a relative clause (13e), or a non-argumental PP (13f):

$$
\begin{aligned}
& \text { a. } 1 \text { é meio no se senté davò *(le) porte } \\
& =3 \mathrm{SG} \text { be. } 3 \text { better not }=3 \text {. REFL sit.INF behind *(the) doors } \\
& \text { 'It's better not to sit behind (the) doors' }
\end{aligned}
$$
b. 1 é tropa mufa davò *(le) doi almierch
$=3 \mathrm{SG}$ be 3 much mold behind $*$ (the) two wardrobes
'There's a lot of mold behind the two wardrobes
c. 1 é na cariega davánt*(1) ultima porta $=3 \mathrm{SG}$ be .3 a chair before $*$ (the) last door
'There's a chair in front of the last door [e.g. in a corridor]'

d. 1 rucsòch 1 é davò *(la) porta rossa the backpack $=3 \mathrm{SG}$ be .3 behind $*$ (the) door red

'The backpack is behind the red door'

e. 1 cián 1 dorm dagnëra sot *(la) taula che $n$ ei scinché the dog $=3$ SG sleep. 3 always under *(the) table that to.us have.2PL given

'The dog always sleeps under the table you gave us'
f. i piac i é su*(la) taola coi piesc de fiern the dishes $=3$ PL be. 3 on $*$ (the) table with.the feet of iron
'The dishes are on the table with iron legs'

Thus, article-drop systematically interacts with internal properties of the nominal complement of the PP. For one thing, it is blocked by overt material intervening between the D-level and the NP. Together with the restrictions noted in 2.1.3 above on the identity of the noun heading the complement, this arguably points to the $\mathrm{N}$ as the central element in determining the properties of the phenomenon.

\subsection{Summary of the explananda}

Summing up, in 2.1 Fodom was shown to have regular article drop in (spatial) PPs. The phenomenon is indeed productive, but only possible with a specific set of nouns. Evidence comes from the availability of article-drop in all structural kinds of PPs attested in Fodom (2.1.1), the possibility of multiple preposition-noun combinations in article-drop contexts (2.1.2), and the insensitivity of article-drop to what $\mathrm{P}$ heads the PP 
(2.1.3). Moreover, it was noted that restrictions apply concerning what noun heads the complement of the PP. The lack of the article is only allowed with nouns that, descriptively, have 'spatially salient' referents (2.1.3). As anticipated, one way to account for this is by taking an underlying morphosyntactic regularity to be at play, which is tied to lexical properties of the relevant nouns.

In 2.2, it was shown that bare nouns in Fodom PPs are ambiguous between a definite and a 'generic'/weak definite reading (2.2.1). Finally, in 2.3 it was shown that article-drop is blocked by plural Number and all nominal modifiers, except for PP arguments. A central part of the analysis will then be to look for an explanation as to why this is the case, and how this can be connected to the issue of what licenses articledrop.

\section{Analysis}

The distribution of article-drop in Fodom proves sensitive both to structural properties of the nominal complement of the PP and to the identity of the head noun. This strongly suggests that the latter plays a central role in the construction. At the core of the account is the idea that the article-drop construction in Fodom involves licensing of a silent D on the part of the noun via the mechanism of phrasal Spell out (cf. Baunaz and Lander 2018a; Caha 2009; 2018; Pantcheva 2011; Starke 2009; 2011; 2018, etc.). This requires taking the specific nouns compatible with article-drop in Fodom to be exceptionally able to realize additional portions of functional structure, as shown in (14) for pòrta "door":

\section{$\left[\mathrm{DP}\left[\mathrm{D}^{\circ}\right]\left[\right.\right.$ ClassP $\left.\left[\text { Class }^{0} \text { PLACE / [+LOC }\right]^{10}\right]\left[\mathrm{NP}\left[\mathrm{N}^{\circ}\right.\right.$ pòrta $\left.\left.\left.]\right]\right]\right]$}

Building on this basic structure, it will be shown that one and the same basic mechanism ( $\mathrm{N}$ spelling out a DP structure) accounts for all properties discussed above.

\subsection{Accounting for the productivity of article-drop}

A systematic presentation of the nanosyntactic approach is beyond the limits of this article and is not central to the present discussion. Informally put, the crucial aspect is that in a nanosyntactic system all lexical items in a language are stored in the lexicon together with the explicit instructions determining the exact amount of structure they can maximally realize, encoded in the form of a so-called L(exical)-tree. Thus, taking the relevant set of nouns to be associated to an L-tree like in (14) straightforwardly captures the lexically restricted nature of the phenomenon. In addition, since a lexical entry can realize a smaller portion of structure than its L-tree, this allows Fodom nouns to lead a double life as regular common count nouns and as bare nouns in the relevant construction.

Moreover, the presence of PLACE/ [+LOC] in (14) explains why article-drop in Fodom is only attested with 'locative' nouns (cf. 2.1), and only in spatial PPs ${ }^{11}$. That is,

10 Whether the structure in (14) indeed contains PLACE or instead a corresponding 'locative' feature is neutral with respect to the present proposal. The issue is accordingly left aside, and so is the question concerning the correct label for the relevant projection.

11 A reviewer objects that this analysis rests on the ad hoc assumption that "the availability of a Phrasal Spell-Out process depends on the lexical specification of a given noun in a specific environment". Now, potential differences in the amount of structure lexicalized by classes of (either lexical or functional) items are directly allowed for by basic nanosyntactic 
the analysis so far accounts for the observation that the phenomenon only occurs with a certain set of nouns, but why are these specific nouns involved, and not others? Second, if something along the lines of what is proposed above is on the right track and these specific nouns are exceptionally capable of Spelling out a D node, why do they do so only in PPs? Recall that no idiosyncrasy was observed on the prepositional component of the construction (2.2.1). Thus, it seems intuitive that this feature of the phenomenon should be connected to some more general property of Ps or PPs. Arguably, these two issues can be given a uniform answer.

As a starting point, I will take locations to be a domain relevant for grammar, with its own formal representation. This assumption is supported by different streams of research on the behavior of nominals in the encoding of spatial relations. Arguably, the basic idea behind it underlies work on silent PLACE in the structure of spatial PPs stemming from Kayne (2004) (e.g. Terzi 2006; Pantcheva 2008; Cinque 2010b), as well as the radically different approach in Matushansky $(2016 ; 2019)$, where classes of 'L(ocative)-nouns' across languages are explicitly analyzed as denoting in the separate domain of loci. In addition, a crosslinguistic tendency for peculiar grammatical behavior of 'locative' nouns has been observed in the typological literature (cf. Stolz, Lestrade, and Stolz 2014; Stolz, Levkovych, and Urdze 2017; Haspelmath 2019). Essentially, this proposal builds on the hypothesis that the relevant difference is represented in syntax and structurally licensed by the relevant nouns within $\mathrm{DP}^{12}$.

A second element for the argument is the distinction of different 'sortal domains' in the semantic ontology of natural language as proposed e.g. in Svenonius (2012) and Ramchand and Svenonius (2014). Specifically, Svenonius (2012) argues for a distinction between a domain of objects, associated to DP structures, and one of locations, identified with part of his decomposition of the spatial PP structure. Departing from the detail of Svenonius's (2012) original proposal, we could rephrase this as the general intuition that the structure of (spatial) PPs requires a structural element performing the shift from the 'sort of objects' to the 'sort of locations'. Taking one step further, in the construction at hand such element might be identified with PLACE acting as a sortal classifier/ontological category (cf. Kayne 2007; Munaro and Poletto 2014; 2020; Baunaz and Lander 2018b; Caha and Pantcheva 2020) or with a corresponding 'locative' feature (cf. n. 6), the other available option being $\mathrm{K}(\mathrm{P})$ (as in Svenonius 2010; 2012).

Now, recall that the special nouns allowing article-drop in Fodom have referents that are 'prototypical parts of locations' (cf. 2.1.3). Above it was argued that this allows one to construe them as elements that can serve pragmatically as points of spatial reference, either in domestic space (e.g. taula "table", almièrch "closet", viere "window", etc.) or in the outdoor space (e.g. plaza "square", gliejia "church", ciampanil "bell tower", etc.). Arguably, one way to capture this structurally would be to hypothesize that these nouns are lexically associated to a structure like in (14). Due to how Spell Out works, this does not imply that they always contain a 'locative' component (PLACE/ [+LOC] in (14)), but only that they must do so whenever they reach the higher D-level, as proposed above.

assumptions. Moreover, no context-dependency in a strict sense is implied. Spell Out is 'blind', and the restriction of article-drop to locative PPs is rather tied to the presence of PLACE / [+LOC] (or whatever they might stand for) in the nominal structure. The issue thus reduces to the plausibility of positing a grammatical representation for 'locations' in the nominal domain, on which cf. below.

12 Of course, this immediately opens questions on the more general role of the projection, its universality, and its position, which will have to be left for future work. 
To see how this unifies the two issues highlighted above, in the present proposal the 'bareness' of the noun is connected to its containing PLACE/ [+LOC] in its structure, which in turn yields a sortal shift to the domain of locations. Thus, the fact that these nouns occur bare only in spatial PPs reduces to the idea that only the latter, and not also e.g. verbs, are compatible with (indeed, require) such shift. Moreover, the same connection between 'bareness' and the presence of PLACE/ [+LOC] is relevant for the issue of why only these nouns, and not others, are allowed to Spell out a D and thus occur bare in spatial PPs. One can now hypothesize that the 'spatial salience' of these nouns could have played a role in a diachronic process that led to their synchronically exceptional behavior. That is, this property might have favored an analysis of these nouns on the part of the speakers as elements that are able to 'eat up' a higher functional layer in the structure hosting PLACE, paving the way to further 'functionalization'. Differently put, with PLACE entering the picture, one can connect the synchronic capability to Spell out a D-node to a diachronic process where a central factor was the 'spatial salience' of these nouns. Arguably, this gives us an answer as to why articledrop in Fodom spatial PPs is only observed with 'locative' nouns ${ }^{13}$.

Now, all this preserves a certain degree of arbitrariness. However, this seems inescapable, given the fact that article-drop in Fodom is evidently subject to lexical restrictions. In addition, potential support might come from two independent sources. First, data indicate that 'complex PPs' (cf. Garzonio and Rossi 2016; 2020) featuring the functional preposition $a$ "to" resist article drop:

\section{(15) 1 é senté davánt (??/*a) viere de cesadafuoch $=3 \mathrm{SG}$ be. 3 sit.PTCP before $(? ? / *$ to) window of kitchen \\ 'He's sitting in front of the kitchen window'}

Recall that in Svenonius's (2012) proposal KP is the structural level where the shift to the 'location' sort is performed. In present terms, a bare noun already contains an element yielding such shift, namely PLACE / [+LOC]. Suppose $a$ "to" is interpreted as realization of K (cf. Svenonius 2006; 2010; 2012), as also suggested by the fact that it is also the general dative marker in Fodom ${ }^{14}$. Then, the present proposal might explain such incompatibility in terms of redundancy. That is, if the two elements compete for encoding the same information/features, the presence of PLACE / [+ LOC] licensed by the noun in its structure would rule out the insertion of the functional $\mathrm{P}^{0} a$ at a later stage.

Second, an interesting parallel might be drawn with temporal PPs in Fodom, although further data is needed. That is, temporal PPs also take bare complements with nouns indicating prototypical moments of the day, as shown in (16)(TALL):

$$
\begin{aligned}
& \text { a. davánt marëna / scòla / mëssa } \\
& \text { before meal / school / Mass } \\
& \text { b. davò mëssa de la domënia } \\
& \text { after Mass of the Sunday }
\end{aligned}
$$

13 Matushansky and Zwarts $(2018 ; 2019)$ interpret nouns with an 'Axial part' use in terms of weak definiteness. This essentially amounts to take them to denote 'locative' kinds. An interesting issue to explore in future work could then be whether what we termed 'locative' nouns in Fodom represent a related stage of diachronic evolution at which the nouns still preserve their nominal nature, while having already acquired partially functional properties.

$14 \quad$ cf. e.g. Franco and Manzini (2018); Caha (2017) on the relation between Case and 'functional' Ps. 
In a nutshell, the hypothesis advanced here lends itself to a straightforward extension to this case as well, modulo the substitution of PLACE with e.g. a TIME counterpart ${ }^{15}$.

\subsection{Accounting for the reading of the noun}

If a D-layer is taken to be active despite appearances, interpretive properties of the noun in article-drop contexts are naturally accommodated within a standard view of Romance DP. Romance nominals are subject to a strict mapping between their syntactic structure and their possible semantic interpretation (cf. e.g. Longobardi 1994; Lyons 1999, etc.), whereby a referential reading is mutually linked to the presence of a D-level in the structure. Accordingly, a bare NP lacking a D level can only denote a property, i.e. behave as an open predicate $(\langle e, t\rangle)^{16}$. Thus, if we take the absence of overt determiners in article-drop contexts at face value and interpret bare nominal complements in Fodom PPs as simple NPs we are left without an explanation of their interpretive properties as presented above.

With an active $\mathrm{D}$ in place, instead, the definite reading we identified in 2.2.1 can be directly accounted for in terms of uniqueness-based (also termed 'inclusive') definiteness (cf. Schwarz 2009; 2013). This involves an iota-operator yielding an individual denotation (Heim and Kratzer 1997) and encoded at the D-level, as is generally the case in Romance. This suffices to account for a possible definite and specific reading of the bare noun in articleless PPs. On the other hand, what we called the 'generic' reading above can be connected to the phenomenon of weak definiteness (Aguilar-Guevara, Le Bruyn, and Zwarts 2014; Carlson and Sussman 2005) ${ }^{17}$.

Interestingly, independent support can be given for this approach, coming from a crosslinguistic tendency noted by Schwarz (2013). Namely, languages systematically encode inclusive definites and weak definites with the same morphological means ${ }^{18}$. Thus, in all cases in which this can be tested, a link between inclusive and weak definiteness emerges, making it perhaps less surprising (and arbitrary) that the interpretive ambiguity identified above should involve precisely these two readings, and not others.

\subsection{Explaining why article-drop is structurally restricted}

To sum up the analysis up to now, given the way Spell Out is taken to work, one and the same idea (the $\mathrm{N}$ also spelling out a $\mathrm{D}$-node) directly accounts for both the

15 The upshot would be that a more abstract and 'conceptually neutral' structure could be maintained for PPs in general, with the relevant differences between, say, spatial and temporal PPs captured in terms of combination with different 'sorts', as those introduced by elements like PLACE and the like, among others. Partially similar considerations are found in Franco and Manzini (2018).

16 Leaving aside the possibility of covert semantic operations type-shifting the denotation of a bare NP e.g. to one of type $\langle e\rangle$. Apart from its ad hoc character, this operation would also appear to violate restrictions on the application of type-shifting operations more in general, e.g. Chierchia's (1998)'Blocking principle’.

17 An interesting possibility could then be to analyze this latter case as involving reference to kinds (cf. e.g. Carlson 1977; Krifka et al. 1995), as put forth by some proposals in the literature (cf. Aguilar-Guevara and Zwarts 2011).

18 In Schwarz (2009), a distinction is proposed between two distinct notions of definiteness in natural language, one based on familiarity/identifiability, while the other on uniqueness/inclusiveness. Among the evidence for this distinction is the fact that certain languages (like Standard German, and, more productively, several German dialects) have distinct ways to express 'anaphoric' and 'inclusive' definiteness. 
interpretive properties of the articleless-PP construction and for the fact that phenomenon is only licensed by a specific set of nouns. Arguably, an optimal result would be achieved if the same hypothesis also turned out to account for the structural restrictions on article-drop described in 2.3.

For the sake of clarity, let us first make explicit the general assumptions at the basis of the derivation. First, it will be assumed that modification within DP is mediated by functional structure, as is common practice in much literature on the topic (cf. e.g. Alexiadou, Haegeman, and Stavrou 2008; Cinque 1994; 2005; 2010b; Laenzlinger 2005; 2015; Svenonius 2008, etc.). Second, a general distinction is assumed to hold between 'default' and 'marked' values for each morphosyntactic category (cf. Cinque 1999). Intuitively, the general consequence is that more or less marked values map onto more or less articulated structural representations (bundles, hierarchies, etc.). Third, it will be assumed that Singular is the default value for Number, and that lack of modification is the default option vis à vis the presence of overt modifiers ${ }^{19}$.

Arguably, the consequence is that a singular non-modified noun heads a DP which is 'maximally simple' in its structure, since only default options are taken. For clarity, let us term this configuration 'slim DP', and take nominal complements in article-drop contexts in Fodom to be 'slim' DPs in this sense. In present terms, this amounts to take them to be lexically associated to a 'slim DP', which is thus the maximum amount of structure they are able to Spell out. This is exactly what was already represented in the structure in $(14)^{20}$, repeated below as the complement of a preposition, as in a basic case like davò pòrta "behind the door":

\section{[PP [Do davò] [DP [Dº ] [ClassP [Classo PLACE / [+LOC]] [NP [No pòrta $]]$ ] ] ]}

Thus, (18) represents the most basic case, where the head spells out a D node in a 'slim'-DP configuration. But what (18) captures is also that a 'slim' DP is the only case in which one of the special nouns in Fodom is able to reach the D-level. Crucially, in the present system plural Number and modifiers introduce marked values/option. Structurally, this means that they require the active presence of intervening functional nodes within the spine of the DP. Once this happens, however, the resulting structure is no longer a 'slim' DP as we defined it. That is, plural Number and nominal modifiers disrupt the structural configuration that is required for the noun to be able to Spell out $\mathrm{D}$, and this accounts for their blocking effect, in that in this case article-drop is necessarily impossible. Since the 'offending' property shared by all elements interacting with article-drop is the sheer presence of additional features/nodes apart from those already present in a 'slim DP', the same reasoning can be replicated for all cases of blocking mentioned in 2.3. For clarity, a representative example is given below, illustrating blocking due to a prenominal adjective $(19 a)(=13 \mathrm{c})$, as represented in the corresponding structure in (19b):

19 An interesting issue is how Gender features might fit in this picture, in light of the fact that article-drop in Fodom is attested with both masculine (e.g. let "bed") and feminine nouns (e.g. taula "table"). The relevant difference might lie in the fact that Gender (unlike e.g. Number) features are specified for each noun as an inherent property. Intuitively, this makes them part of the 'default' information represented in the structure of any noun, and thus neutral with respect to the default vs. marked distinction adopted in the present proposal. Further details (including the precise role of affixes) will have to be left for future work.

$20 \quad$ For convenience, here the representation presupposes that all default options are simply absent, essentially in the spirit of Starke (2004), but this is not crucial for the analysis. 
a. 1 é na cariega davánt *(1) ultima porta $=3 \mathrm{SG}$ be .3 a chair before $*($ the $)$ last door

'There's a chair in front of the last door [e.g. in a corridor]'

b.

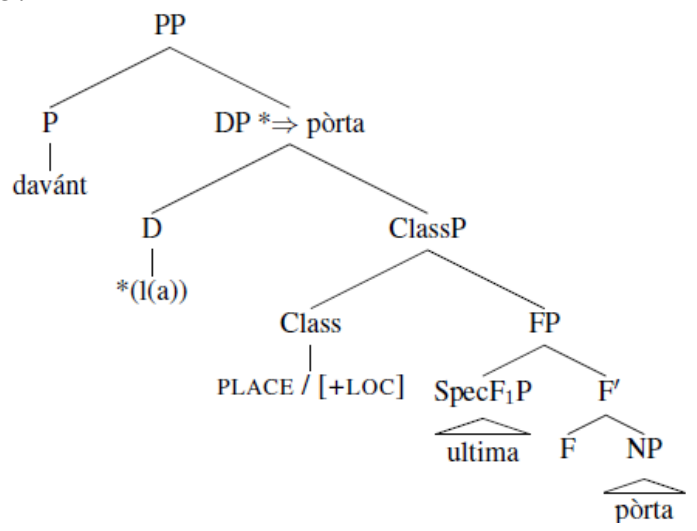

The last bit concerns argumental PPs. As shown in 2.3, PP arguments of the noun are the only DP-internal elements that do not block article-drop. Arguably, the present system is already capable to account for this difference. It is pretty much common practice to assume a distinction between PP-modifiers/adjuncts and PParguments of the noun, with the latter entering the structure in the low, lexical projection headed by the nominal head (i.e. nP/NP, cf. e.g. Alexiadou, Haegeman, and Stavrou 2008) ${ }^{21}$. Thus, PP-arguments are merged within a category already projected/realized by the lexical nominal head. What is relevant for present purposes is that this has the consequence that they do not require additional functional nodes to enter the structure. Thus, argumental PPs preserve the structural configuration we termed 'slim' $\mathrm{DP}^{22}$. In the present account, this suffices to tease them apart from all other DP-internal elements.

However, at a greater level of technical detail this case involves one additional step. What is required is the application of an operation which is part of the so-called 'Spell Out algorithm' as in use in nanosyntactic literature (cf. 3.1.3). This essentially means manipulating the syntactic structure by displacing the problematic item (in our case, the PP argument in Spec NP) via an application of 'meaningless movement'. Interestingly, essentially this same mechanism, also termed 'extraposition of the arguments' (cf. e.g. Caha, 2018) is assumed by Cinque $(2005,2010 \mathrm{~b})$ in his roll-up movement analysis of the order of modifiers in the structure of DPs ${ }^{23}$. That is, although it might look undesirable, this further step is not specific to the present proposal, as it has parallels both within and outside nanosyntactic literature. For the sake of explicitness, the derivation of a PP like in (20) is exemplified in (21) below:

$$
\begin{aligned}
& \text { a. nte almièrch de mia ciauna è cialé } \\
& \text { in wardrobe of my room have.1SG already watch.PTCP } \\
& \text { 'I've already checked in my bedroom closet' }
\end{aligned}
$$

21 In a nutshell, the main motivation comes from considerations of parallelism with the clausal domain and patterns of extraction (cf. also Cinque 1980).

22 As noted by one reviewer, some version of this idea might be seen as a way to translate the traditional notion of 'L-marking' (Chomsky 1986).

23 Modulo the fact that in Cinque's analysis movement of the P-argument out of NP is connected to the presence of a higher $\mathrm{P}^{0}$ head (outside the $\mathrm{D}$-level), which attracts the argument along the lines of Kayne's (2001) theory of 'prepositions as probes'. 
(20) a. [DP [ClassP [+LOC] [NP [PP de mia ciauna] almièrch]] ]

$\rightarrow$ 'extraposition' of the PP argument out of the DP:

b. [ [PP de mia ciauna]i [DP [ClassP [+LOC] [NP $\left.t_{\text {i almièrch }]]]}\right]$

$\rightarrow$ roll-up movement of DP yielding the observed linear order:

c. [PP nte [DP [DP [ClassP [+LOC] [NP $t_{\mathrm{i}}$ almièrch]]]]j [ [PP de mia ciauna $\left.\left.]_{\mathrm{i}}\left[\mathrm{DP} t_{\mathrm{j}}\right]\right]\right]$

The relevant point is that 'extraposition' restores a structural configuration that allows the head noun (here, almièrch) to Spell out both the NP and the $\mathrm{DP}^{24}$, because the PP de mia ciauna ends up in a position that no longer 'stands in the way' between $\mathrm{D}$ and the NP. Crucially, this same operation is not able to circumvent the blocking effect of other modifiers, because their evacuation would still leave intervening functional XPs between NP and D. This directly follows in the present system, which can thus be claimed to capture in a uniform way all aspects of the distribution of Fodom articledrop.

\subsection{Rejecting alternative analyses}

The approach pursued here should be compared to at least two potential alternatives. Namely, it could be a priori preferable to connect licensing of article-drop to other independently needed mechanisms, like selection, or movement. For instance, since the phenomenon is only attested in PPs, an intuitive possibility could be to take the $\mathrm{P}^{0}$-head to license a null article or an empty $\mathrm{D}^{0}$-head under selection, as schematically represented below:

$$
\left[\mathrm{PP}\left[\mathrm{P}^{\circ} \text { davò }\right]\left[\mathrm{DP}\left[\mathrm{D}^{\circ} \mathrm{e}\right]\left[\ldots\left[\mathrm{NP}\left[\mathrm{N}^{\circ} \text { pòrta }\right]\right]\right]\right]\right]
$$

In a nutshell, such analysis would face three problems. The first concerns the issue of how to properly restrict the distribution of such $\mathrm{D}^{0} \mathrm{e} /$ covert article so that it could only occur with PPs, and not in an argumental position. Second, focusing on properties of $\mathrm{P}^{0}$ and $\mathrm{D}^{0}$ provides no explanation as to why article-drop is only observed with certain nouns, and not others. Third, this kind of approach would not explain why plural number and nominal modifiers require the realization of the article.

A second imaginable option could be to take movement of the noun (N or NP) to the D-level to be the relevant mechanism licensing covert D in Fodom articleless PPs. The relevant set of nouns could be taken to be able to raise higher than other common nouns in their extended projection, although this would still need to be somehow encoded as a property of their lexical entries. Moreover, such exceptional movement of the noun would account neither for the fact that omission is restricted to PPs, nor for the blocking effects observed. While canonical cases of N-to-D in Romance are indeed restricted to the singular, the restriction doesn't extend to nominal modifiers (cf. e.g. Longobardi 1994 and ff. for N-to-D, and Cinque 2004 for NP-to SpecDP in Romanian), and actually it is precisely this fact that supports a movement analysis in the corresponding cases. Thus, the two cases are crucially different, which makes an extension of a movement analysis unsuitable for bare nouns in Fodom PPs.

24 This is possible because, as standard in much nanosyntactic work, Spell-out is assumed not to be sensitive to traces. As a consequence, an NP with no argument and a remnant NP with the trace of an extraposed argument are not distinguished. 


\section{Conclusion}

To sum up, the only hypothesis specific to this proposal (i.e. attributing exceptional Spell Out properties to this set of nouns) succeeds in reducing the different empirical observations outlined above to the same source. The interpretive properties of the noun are accounted for by the presence of a silent D-layer, within a standard view of Romance DPs. The presence of PLACE (or of a corresponding [+LOC] feature) explains both the availability of article-drop only in spatial PPs and the restriction to a set of 'locative' nouns. Finally, the mechanism of Spell Out allows us to derive structural restrictions on the omission of the article in terms of structural blocking. The present account in terms of Spell Out properties of the noun was argued to fare better than alternatives in terms of empty/null-D licensing under selection by $\mathrm{P}^{0}$ or via N-to-D/NPto-SpecDP movement, both empirically and conceptually.

A key ingredient in the derivation proposed here is the idea that singular nonmodified nouns correspond to a DP structure which is maximally simple, here termed 'slim' DP. As shown above, this directly captures the fact that article-drop is only attested with specific nouns and without overt modifiers as the result of a purely structural restriction. Thus, 'slim' DPs can represent a valuable tool to analyze interactions among lexical heads and the highest layers of the extended projection more in general, and specifically where 'bareness' (the lack of a functional item like an article, a case marker, or a P) correlates with restrictions on modification (e.g. in the patterns studied by Matushansky 2016; 2019).

Finally, some of the features of Fodom article-drop seem to partially overlap with those of other phenomena, like article-drop in Romanian (cf. e.g. Mardale 2006) and the more widespread case of 'bare PPs' (cf. Baldwin et al. 2006; Carlson and Sussman 2005; De Swart 2015; Stvan 1998). However, important differences emerge at closer inspection, the two main ones being that article-drop in Fodom (unlike 'bare' PPs crosslinguistically) is not limited to functional Ps like in or at, and on the other hand is only compatible with specific nouns (unlike in Daco-Romance varieties, where it is generalized). It would be interesting to verify to what extent a connection between all these cases would be grounded, and whether the system developed here for Fodom can be adjusted to capture the relevant differences between all these cases. The exploration of these and related issues is left for future work.

\section{References}

Aguilar-Guevara, Ana, Bert Le Bruyn \& Joost Zwarts. 2014. Advances in Weak Referentiality. In Weak Referentiality, edited by Ana Aguilar-Guevara, Bert Le Bruyn, and Joost Zwarts, 219:1-16. John Benjamins Publishing Company.

Aguilar-Guevara, Ana \& Joost Zwarts. 2011. Weak Definites and Reference to Kinds. In Semantics and Linguistic Theory, 20:179-96.

Alexiadou, Artemis, Liliane Haegeman \& Melita Stavrou. 2008a. Noun Phrase in the Generative Perspective. Vol. 71. Walter de Gruyter.

Alexiadou, Artemis, Liliane Haegeman \& Melita Stavrou. 2008b. Noun Phrase in the Generative Perspective. Vol. 71. Walter de Gruyter. 
Asbury, Anna, Berit Gehrke, Henk van Riemsdijk \& Joost Zwarts. 2008. Introduction: Syntax and Semantics of Spatial P. In Linguistik Aktuell/Linguistics Today, edited by Anna Asbury, Jakub Dotlačil, Berit Gehrke, and Rick Nouwen, 120:1-32. Amsterdam: John Benjamins Publishing Company. https://doi.org/10.1075/la.120.01asb.

Baldwin, Timothy, Beavers John, van der Beek Leonoor, Bond Francis, Flickinger Dan \& Ivan A. Sag. 2006. In Search of a Systematic Treatment of Determinerless PPs. In Syntax And Semantics of Prepositions. Text, Speech And Language Technology, edited by P Saint-Dizier. Springer.

Baunaz, Lena \& Eric Lander. 2018a. Nanosyntax: The Basics. In Exploring Nanosyntax, edited by Lena Baunaz, Liliane Haegeman, Karen De Clercq, and Eric Lander, 3-56. Oxford University Press.

Baunaz, Lena \& Eric Lander. 2018b. Ontological Categories. In The Unpublished Manuscript: A Collection of LingBuzz Papers to Celebrate Michal Starke's 50th Birthday, edited by Lena Baunaz, Eric Lander, Pavel Caha, Karen de Clercq, and Guido Vanden Wyngaerd. LingBuzz.

Caha, Pavel. 2009a. The Nanosyntax of Case. PhD Thesis, Universitetet i Troms $\varnothing$.

Caha, Pavel. 2017. How (Not) to Derive a *ABA: The Case of Blansitt's Generalisation. Glossa: A Journal of General Linguistics 2 (1): 84. https://doi.org/10.5334/gjgl.348.

Caha, Pavel. 2018. "Notes on Insertion in Distributed Morphology and Nanosyntax." In Exploring Nanosyntax, edited by Lena Baunaz, Liliane Haegeman, Karen De Clercq, and Eric Lander, 57-87. Oxford University Press New York.

Caha, Pavel \& Marina Pantcheva. 2020. Locatives in Shona and Luganda. to appear in: Variation in P: Comparative Approaches to Adpositional Phrases, edited by Jacopo Garzonio and Silvia Rossi. Oxford University Press, USA.

Carlson, Gregory. 1977. Reference to Kinds in English. PhD Thesis, University of Massachussets Amherst.

Carlson, Gregory \& Rachel Sussman. 2005. Seemingly Indefinite Definites. In Linguistic Evidence: Empirical, Theoretical, and Computational Perspectives, edited by Kepser Stephan and Marga Reis, 71-85. de Gruyter Berlin.

Casalicchio, Jan. 2020a. Il Ladino e i Suoi Idiomi. In Manuale Di Linguistica Ladina, edited by Videsott P., Videsott R. \& J. Casalicchio, 144-201. De Gruyter.

Casalicchio, Jan. 2020b. Ladinia Dolomitica. In Lo Spazio Comunicativo Dell'Italia e Delle Varietà Italiane, edited by T. Krefeld \& R. Bauer.

Chierchia, Gennaro. 1998. Reference to Kinds across Language. Natural Language Semantics 6 (4): 339-405. 
Chomsky, Noam. 1986. Barriers. Linguistic Inquiry Monographs 13. Cambridge, Mass: MIT Press.

Cinque, Guglielmo. 1980. On Extraction from NP in Italian. Journal of Italian Linguistics, 1980.

Cinque, Guglielmo. 1994. On the Evidence for Partial N-Movement in the Romance DP. In Paths towards Universal Grammar. Studies in Honor of Richard S. Kayne. Georgetown University Press.

Cinque, Guglielmo. 1999. Adverbs and Functional Heads: A Cross-Linguistic Perspective. Oxford University Press.

Cinque, Guglielmo. 2004. A Phrasal Movement Analysis of the Romanian DP. Studia Linguistica et Philologica in Honorem D. Irimia, pp. 129-142.

Cinque, Guglielmo. 2005a. Deriving Greenberg's Universal 20 and Its Exceptions. Linguistic Inquiry 36 (3): 315-32.

Cinque, Guglielmo. 2010a. Mapping Spatial PPs: An Introduction. In Mapping Spatial PPs. The Cartography of Syntactic Structures, edited by G. Cinque and L. Rizzi, 6:3-25. Oxford University Press.

Cinque, Guglielmo. 2010b. The Syntax of Adjectives: A Comparative Study. Vol. 57. MIT press.

De Swart, Henriette. 2015. Constructions with and without Articles. In The Syntax and Semantics of Pseudo-Incorporation, edited by Olga Borik and Berit Gehrke, 12656. Brill.

Franco, Ludovico, and Paolo Lorusso. 2019. The Expression of Proper Location and beyond: Motion-to and State-in in Italian Spatial Adpositions. In Proceedings of the 49 $9^{\text {th }}$ Meeting of the North East Linguistic Sociey (NELS49), edited by Maggie Baird and Jonathan Pesetsky. GLSA (Graduate Linguistics Student Association), Department of Linguistics, University of Massachusetts.

Franco, Ludovico \& M Rita Manzini. 2018. Locative Ps as General Relators: Location, Direction, DOM in Romance.

Garzonio, Jacopo \& Silvia Rossi. 2016. Case in Italian Complex PPs. Romance Languages and Linguistic Theory 10: 121-38.

Garzonio, Jacopo \& Silvia Rossi. 2020. "AxParts and Case in Complex PPs: Microvariation in Italian Dialects." In Variation in P: Comparative Approaches to Adpositional Phrases, edited by Jacopo Garzonio and Silvia Rossi, 84-113.

Heim, Irene \& Angelika Kratzer. 1997. Semantics in Generative Grammar. Blackwell Textbooks in Linguistics 13. Malden, MA: Blackwell.

Kayne, Richard. 2001. Prepositions as Probes, Ms. New York University. 
Kayne, Richard. 2004. Here and There. In Syntax, Lexis \& Lexicon-Grammar: Papers in Honour of Maurice Gross, 253-73. John Benjamins.

Kayne, Richard. 2007. Here and There. In Movement and Silence. United Kingdom: Oxford University Press. https://doi.org/10.1093/acprof:oso/9780195179163.003.0004.

Krifka, Manfred, Francis Jeffry Pelletier, Gregory Carlson, Alice Ter Meulen, Gennaro Chierchia, and Godehard Link. 1995. Genericity: An Introduction. In The Generic Book, edited by Gregory Carlson and Francis Jeffry Pelletier.

Laenzlinger, Christopher. 2005. Some Notes on DP-Internal Movement. GG@ G 4: 227-60.

Laenzlinger, Christopher. 2015. The CP/DP Parallelism Revisited. In Beyond Functional Sequence: The Cartography of Syntactic Structures, edited by Ur Shlonsky. Vol. 10. Oxford University Press.

Longobardi, Giuseppe. 1994. Reference and Proper Names: A Theory of N-Movement in Syntax and Logical Form. Linguistic Inquiry, 609-65.

Lyons, Christopher. 1999. Definiteness. Cambridge University Press.

Mardale, Alexandru. 2006. On the Use of the Definite Article with Prepositions in Romanian.

Matushansky, Ora. 2016. The Definite Article in Proper Places. Workshop on the semantic contribution of Det and Num.(In) definiteness, genericity and referentiality).

Matushansky, Ora. 2019. The Case of Restricted Locatives. Proceedings of Sinn Und Bedeutung, July, 161-178 Pages. https://doi.org/10.18148/SUB/2019.V23I2.604.

Matushansky, Ora \& Joost Zwarts. 2018. The Partial Nominality of Axial Parts. Handout. Talk Presented on February 16th at Universitat Pompeu Fabra. www.Trees-and-Lambdas.Info/Matushansky/Downloads/Axial-HandoutSIM.Pdf.

Matushansky, Ora \& Joost Zwarts.2019. Tops and Bottoms: Axial Nominals as Weak Definites. In Proceedings of the 36th West Coast Conference on Formal Linguistics, 270-80. Cascadilla Proceedings Project.

Munaro, Nicola \& Cecilia Poletto. 2014. Synchronic and Diachronic Clues on the Internal Structure of 'where' in Italo-Romancelast. In Diachrony and Dialects, 279-300. Oxford University Press. https://doi.org/10.1093/acprof:oso/9780198701781.003.0014.

Munaro, Nicola \& Cecilia Poletto. 2020. Prepositional 'Where' in Southern Italian Dialects. In Variation in $P, 114-32$. Oxford University Press. https://doi.org/10.1093/oso/9780190931247.003.0005. 
Pantcheva, Marina Blagoeva. 2008. The Place of PLACE in Persian. In Linguistik Aktuell/Linguistics Today, edited by Anna Asbury, Jakub Dotlačil, Berit Gehrke, and Rick Nouwen, 120:305-30. Amsterdam: John Benjamins Publishing Company. https://doi.org/10.1075/la.120.16pan.

Pantcheva, Marina Blagoeva. 2011. Decomposing Path: The Nanosyntax of Directional Expressions. PhD Thesis, Universitetet i Troms $\varnothing$.

Ramchand, Gillian \& Peter Svenonius. 2014. Deriving the Functional Hierarchy. Language Sciences 46: 152-74.

Schwarz, Florian. 2009. Two Types of Definites in Natural Language. PhD Thesis, University of Massachusetts Amherst.

Schwarz, Florian. 2013. Two Kinds of Definites Cross-Linguistically. Language and Linguistics Compass 7 (10): 534-59.

Starke, Michal. 2004. On the Inexistence of Specifiers and the Natures of Heads. In Structures and Beyond. The Cartography of Syntactic Structures, edited by Adriana Belletti. Vol. 3. Oxford, Oxford University Press.

Starke, Michal. 2009. Nanosyntax: A Short Primer to a New Approach to Language, Ms.

Starke, Michal. 2011. Towards an Elegant Solution to Language Variation: Variation Reduces to the Size of Lexically Stored Trees. Ms., Troms $\phi$ University.

Starke, Michal. 2018. Complex Left Branches, Spellout, and Prefixes. In Exploring Nanosyntax, edited by Lena Baunaz, Liliane Haegeman, Karen De Clercq, and Eric Lander, 239-49. Oxford University Press.

Stvan, Laurel. 1998. The Semantics and Pragmatics of Bare Singular Noun Phrases. $\mathrm{PhD}$ Thesis, Northwestern University.

Svenonius, Peter. 2006. The Emergence of Axial Parts. Ms.

Svenonius, Peter. 2008. The Position of Adjectives and Other Phrasal Modifiers in the Decomposition of DP. In Adjectives and Adverbs, edited by McNally L. and C. Kennedy, 16-42. Oxford University Press.

Svenonius, Peter. 2010. Spatial p in English. In Mapping Spatial PPs: The Cartography of Syntactic Structures, edited by G. Cinque and L. Rizzi, 6:127-60. Oxford University Press Oxford.

Svenonius, Peter. 2012. Structural Decomposition of Spatial Adpositions. Work. Pap., Dep. Linguist., Univ. Tromsф, Nor. Http://Www. Linguistics. Rub. de/TheMeaningofP2012/Svenonius_Handout.Pdf.

“TALL Corpuslad.” n.d. http://corpuslad.ladintal.it/applications/textanalysis/search.jsp. 
Talmy, Leonard. 1975. Semantics and Syntax of Motion. In Syntax and Semantics Volume 4, edited by John P. Kimball, 181-238. BRILL. https://doi.org/10.1163/9789004368828_008.

Terzi, Arhonto. 2006. The Misleading Status of Locative Prepositions. Technological Educational Institute of Patras. 